\title{
Prevalence, awareness, treatment and control of hypertension in the elderly population of Singapore
}

\begin{abstract}
Rahul Malhotra ${ }^{1}$, Angelique Chan ${ }^{1,2}$, Chetna Malhotra ${ }^{1}$ and Truls Østbye $\mathrm{e}^{1,3}$
A comprehensive picture of the management of hypertension in the increasing elderly population in Singapore is lacking. In this study, we assess the prevalence and correlates of hypertension and of awareness, treatment and control of hypertension among 4494 elderly Singaporeans ( $\geqslant 60$ years) participating in a recent representative survey. The weighted prevalences of hypertension (systolic blood pressure $\geqslant 140 \mathrm{~mm} \mathrm{Hg}$ or diastolic blood pressure $\geqslant 90 \mathrm{~mm} \mathrm{Hg}$ or current use of antihypertension medication) and of awareness, treatment and control of hypertension were assessed. We assessed the extent of association of these outcomes with socio-demographic (age, gender, ethnicity, education, housing type, living arrangement and social participation) and health (body mass, diabetes and cognitive status) variables using multivariable logistic regression. Nearly three-fourths (73.9\%) of participants were found to have hypertension. Of this number, $30.8 \%$ were unaware that they had hypertension, $32.0 \%$ were not being treated for the disease and $75.9 \%$ had suboptimal control of their blood pressure. Among those aware of their hypertension, only $1.9 \%$ were untreated. However, nearly two-thirds (64.5\%) of treated hypertensives had suboptimal control. Age, gender, ethnicity, education, housing type, body mass and diabetes were significantly correlated with lack of awareness, treatment and control of hypertension. Although the specific 'at-risk' subgroups varied by the outcome, men and Malays had consistently higher odds for all three unfavorable outcomes. There is a need to improve awareness, treatment and especially control of hypertension among elderly Singaporeans. Primary and secondary prevention efforts targeting the
\end{abstract} elderly and their primary health-care providers are called for, as are regular data collection efforts based on representative samples.

Hypertension Research (2010) 33, 1223-1231; doi:10.1038/hr.2010.177; published online 30 September 2010

Keywords: Asia; blood pressure; health survey; Singapore

\section{INTRODUCTION}

Hypertension, a major cardiovascular risk factor, ${ }^{1,2}$ is also the leading risk factor for adult mortality worldwide. ${ }^{3}$ The elderly constitute an important group in the epidemiology of hypertension. Of all age groups, they have the highest prevalence of hypertension ${ }^{4-6}$ and are at particularly high risk of hypertension-related diseases. ${ }^{1,7}$ In fact, individuals who are normotensive at age 55 have a $90 \%$ lifetime risk of developing hypertension. ${ }^{8}$ However, hypertension among the elderly is treatable, $2,9,10$ and lowering blood pressure (BP) among elderly hypertensives, even the very old, can reduce the incidence of major coronary events and stroke. ${ }^{1,7,9,11,12}$ In fact, morbidity and mortality benefits derived from treatment may be even higher and may be appreciated earlier for older hypertensives. ${ }^{10,13}$ However, despite the effectiveness of treatment, studies report that elderly hypertensives have the lowest levels of BP control compared with younger hypertensives, even if they are more aware of their hypertensive status and more likely to be under pharmacological treatment., ${ }^{4,6}$

Recognizing the elderly as an at-risk population, studies in various countries have documented the prevalence and correlates of hypertension and of awareness, treatment and control of hypertension among the elderly. ${ }^{14-27}$ These studies suggest considerable heterogeneity for the prevalence of these conditions across elderly subgroups, defined by socio-demographic or health characteristics. Furthermore, neither the prevalence nor the identified correlates are uniform across countries. The variation could result from differences in criteria for defining hypertension and its treatment, but could also reflect variations in demographic and health profiles of the elderly as well as access to health services for chronic disease detection and management across countries. Therefore, it is important to have country-specific data for planning hypertension detection and management services for the elderly, especially for countries that have or will soon have a sizable elderly population.

Singapore is an aging country. The proportion of elderly Singaporeans aged $\geqslant 60$ years (currently around $10 \%$ ) is projected to double by 2030. ${ }^{28,29}$ However, a comprehensive picture of the management of hypertension among elderly Singaporeans is lacking. Previous studies have not been nationally representative, ${ }^{6,16,18}$ and either do not focus exclusively on the elderly ${ }^{6}$ or only present the prevalence and

\footnotetext{
${ }^{1}$ Health Services and Systems Research, Duke-National University of Singapore Graduate Medical School, Singapore; ${ }^{2}$ Department of Sociology, National University of Singapore, Singapore and ${ }^{3}$ Department of Community and Family Medicine, Duke University Medical Center, Durham, NC, USA 
correlates of undetected hypertension. ${ }^{18}$ The latest Singapore National Health Survey, ${ }^{30}$ conducted in 2004, did assess the prevalence of hypertension and its treatment in a nationally representative sample, but only subjects $<70$ years old were included.

Taking advantage of a recent, large, representative survey, the present analyses were conducted to assess the prevalence and correlates of hypertension and of awareness, treatment and control of hypertension among elderly Singaporeans.

\section{METHODS}

\section{Singapore Social Isolation, Health and Lifestyles Survey (SIHLS)} 2009

The SIHLS, a nationally representative survey of community-dwelling elderly Singaporeans, was conducted in 2009 for the Ministry of Community Development, Youth and Sports. The target sample size was 5000. Assuming a $60 \%$ response rate, based on previous surveys of the elderly in Singapore, a random sample of 8400 elderly people stratified by gender, ethnicity and age (divided into 5-year increments: 60-64, 65-69, ..., 85+) according to the 2007 population distribution was drawn from the national database of dwellings. People $\geqslant 75$ years old, Malays and Indians were oversampled by a factor of two to ensure a sufficient number in these subgroups for analysis. A total of 1195 (14.2\%) addresses in the sample were found to be invalid. Of the rest, 5000 elderly people were interviewed face to face at their residence with informed consent using a structured questionnaire, yielding a response rate of $69.4 \%$. The nonrespondents (refusal to participate $(59.1 \%$ ) and those who could not be contacted even after a minimum of three household visits (40.9\%)) were more likely to be $<70$ years old and to represent 'other' ethnic groups but were similar in gender distribution compared with respondents. Proxy interviews were conducted for 458 (9.2\%) elderly people who were unable to respond due to health reasons.

\section{BP measurement}

To insure consistency in BP measurement, interviewers were trained using didactic instruction, training videos and role-plays. Three resting BP measurements approximately $1 \mathrm{~min}$ apart were taken for 4494 (89.9\%) participants using an electronic BP monitor (Omron HEM-780N, Omron, Kyoto, Japan). The rest ( $n=506$ ), for whom BP could not be measured (refusal; cast/rash/wound/edema/ bruise on $\operatorname{arm}(\mathrm{s})$ ), were excluded from further analysis. Those excluded were more likely to be older, Chinese and have no formal education but were similar in gender distribution to the rest of the sample. Nearly all BP measurements were taken in accordance with the instructions given (left arm and sitting position used for 98.3 and $99.1 \%$ of participants, respectively). The mean of the three readings was used to define the systolic $\mathrm{BP}$ (SBP) and diastolic $\mathrm{BP}$ (DBP) values.

\section{Definitions}

The prevalence of BP classes, as defined in the Joint National Committee on Prevention, Detection, Evaluation and Treatment of High Blood Pressure (JNC-7) guidelines, was assessed: normal (SBP $<120 \mathrm{~mm} \mathrm{Hg}$ and DBP $<80 \mathrm{~mm} \mathrm{Hg}$ ), prehypertension (SBP $120-139 \mathrm{~mm} \mathrm{Hg}$ or DBP $80-89 \mathrm{~mm} \mathrm{Hg}$ ), stage 1 hypertension (SBP $140-159 \mathrm{~mm} \mathrm{Hg}$ or DBP $90-99 \mathrm{~mm} \mathrm{Hg}$ ) and stage 2 hypertension (SBP $\geqslant 160 \mathrm{~mm} \mathrm{Hg}$ or DBP $\geqslant 100 \mathrm{~mm} \mathrm{Hg}$ ). ${ }^{1}$ The classification was based on measured BP (irrespective of treatment status), assigning the participant to the higher category if he/she could be classified into two categories.

In accordance with previous surveys and guidelines, hypertension was defined as 'SBP $\geqslant 140 \mathrm{~mm} \mathrm{Hg}$ or DBP $\geqslant 90 \mathrm{~mm} \mathrm{Hg}$ or (self-reported) current use of anti-hypertension medication.' ${ }^{1,14,15,17,19-27}$ Among hypertensives, those who responded in the negative to 'Have you ever been diagnosed with high blood pressure by a medical professional?' were considered to be unaware and those who responded in the negative to 'Are you presently taking any medicine prescribed by a physician for high blood pressure?' were classified as untreated. Thus, untreated participants included both those unaware of their hypertension and those who were aware but were not receiving any antihypertension medication. The extent of BP control was ascertained among all hypertensives and among treated hypertensives, with SBP and DBP values for defining control varying by (self-reported) diabetes status. For elderly subjects without diabetes, SBP $<140 \mathrm{~mm} \mathrm{Hg}$ and DBP $<90 \mathrm{~mm} \mathrm{Hg}$ was considered to represent controlled $\mathrm{BP}$, whereas corresponding values for elderly subjects with diabetes were SBP $<130 \mathrm{~mm} \mathrm{Hg}$ and DBP $<80 \mathrm{~mm} \mathrm{Hg}$, based on JNC-7 guidelines, ${ }^{1}$ clinical practice guidelines for hypertension in Singapore $^{31}$ and previous studies. ${ }^{19,23}$ Those exceeding the criteria were considered as having suboptimal BP control.

\section{Correlates}

A variety of socio-demographic and health variables, evaluated as potential correlates with hypertension and/or awareness, treatment and control of hypertension in previous studies, ${ }^{6,14-27,32}$ were evaluated as correlates in the present analysis.

The socio-demographic variables included age (60-64 years, 65-74 years and $\geqslant 75$ years), gender, ethnicity, education, housing type, living arrangement (based on household composition) and level of social participation. The three main ethnic groups in Singapore, that is, Chinese, Malay and Indian, were considered in the analysis. Those representing the 'Other' ethnic groups ( $n=53$ out of the 4494 with measured BP values) were excluded as their number was too small for meaningful comparison. Education was categorized as none, primary, secondary and > secondary (vocational/technical/junior college/polytechnic/university education). Housing type was classified as public (Housing Development Board housing-further classified by the number of rooms ( 1 to 2,3 and $\geqslant 4$ )) - or private (condominiums) or other (bungalow/ terrace house/semidetached house/shophouse). A social participation score was calculated based on frequency of participation (not at all (0), less than once a month (1), every month (2), every week (3), every day (4) in three social activities: attending neighborhood events, eating out and attending a place of worship) and divided into tertiles for the analysis. The health variables were body mass category (body mass index (BMI), based on measured weight and height, was categorized using Asian cutoffs, ${ }^{33,34}$ that is, underweight $\left(<18.5 \mathrm{~kg} \mathrm{~m}^{-2}\right)$, low risk (healthy range; $\left.18.5-22.9 \mathrm{~kg} \mathrm{~m}^{-2}\right)$, moderate/increased risk $\left(23.0-27.4 \mathrm{~kg} \mathrm{~m}^{-2}\right)$ and high risk $\left(\geqslant 27.5 \mathrm{~kg} \mathrm{~m}^{-2}\right)$ ), diabetes (doctor-diagnosed, self-reported status) and cognitive status (intact, mild cognitive impairment and moderate/severe cognitive impairment, based on subjects' SPMSQ (Short Portable Mental Status Questionnaire $)^{35}$ score).

\section{Statistical analysis}

Weighted proportion and mean estimates were calculated for categorical and continuous variables, respectively. The presence of a significant difference in means across levels of categorical variables was detected using either an unpaired $t$-test or analysis of variance. An $\chi^{2}$ test was used for assessing significant difference in proportions across levels of categorical variables. A $P$-value of $<0.05$ was considered to be statistically significant. Association of potential socio-demographic and health correlates with the presence of hypertension and subjects' awareness, treatment and control of hypertension was ascertained using multivariable logistic regression analysis. The analysis, conducted using SAS for Windows Version 9.2 (SAS, Cary, NC, USA) was weighted using survey-sampling weights to adjust for nonresponse and oversampling.

\section{Ethical approval}

The present analysis, based on de-identified data, was exempted from full review by the institutional review boards of the National University of Singapore and Duke University Health System.

\section{RESULTS}

Study population characteristics

The socio-demographic and health characteristics of 4441 elderly Singaporeans (excluding 53 categorized by ethnic group as 'Other') are given in Table 1.

\section{Mean SBP and DBP, and JNC-7 BP classification}

Although SBP increased significantly with age, there was a significant decline with age in DBP. In addition, although SBP was similar for 
Table 1 Socio-demographic and health characteristics of the study population

\begin{tabular}{|c|c|}
\hline Characteristic & $\begin{array}{c}\text { Weighted \% (n) }{ }^{\mathrm{a}} \text {, } \\
\qquad \mathrm{N}=4441\end{array}$ \\
\hline \multicolumn{2}{|l|}{ Age group (in years) } \\
\hline $60-64$ & $33.5(897)$ \\
\hline $65-74$ & $42.7(1758)$ \\
\hline$\geqslant 75$ & $23.8(1786)$ \\
\hline \multicolumn{2}{|l|}{ Gender } \\
\hline Male & $45.7(2027)$ \\
\hline Female & $54.3(2414)$ \\
\hline \multicolumn{2}{|l|}{ Ethnicity } \\
\hline Chinese & $83.4(3154)$ \\
\hline Malay & $10.0(797)$ \\
\hline Indian & $6.6(490)$ \\
\hline \multicolumn{2}{|l|}{ Education } \\
\hline None & $30.0(1576)$ \\
\hline Primary & $37.3(1644)$ \\
\hline Secondary & $23.8(900)$ \\
\hline More than secondary ${ }^{c}$ & $8.7(310)$ \\
\hline \multicolumn{2}{|l|}{ Housing type } \\
\hline 1-2 room HDB & $7.6(396)$ \\
\hline 3 room HDB & 26.7 (1207) \\
\hline$\geqslant 4$ rooms $\mathrm{HDB}$ & $53.0(2283)$ \\
\hline Condominium & $5.2(220)$ \\
\hline Other ${ }^{d}$ & $7.6(335)$ \\
\hline \multicolumn{2}{|l|}{ Living arrangement } \\
\hline Alone/with maid or others & $12.0(513)$ \\
\hline With spouse only & $18.9(800)$ \\
\hline With both spouse and children & $43.5(1718)$ \\
\hline With children only & $25.6(1410)$ \\
\hline \multicolumn{2}{|l|}{ Social participation } \\
\hline 1 st tertile (least) & $24.3(1257)$ \\
\hline 2nd tertile & $43.9(1868)$ \\
\hline 3rd tertile (most) & $31.8(1316)$ \\
\hline \multicolumn{2}{|l|}{ Body mass category } \\
\hline Underweight $\left(<18.5 \mathrm{~kg} \mathrm{~m}^{-2}\right)$ & $6.7(318)$ \\
\hline Low risk (healthy range) $\left(18.5-22.9 \mathrm{~kg} \mathrm{~m}^{-2}\right)$ & $32.5(1387)$ \\
\hline Moderate risk (23.0-27.4 $\mathrm{kg} \mathrm{m}^{-2}$ ) & $39.7(1696)$ \\
\hline High risk ( $\geqslant 27.5 \mathrm{~kg} \mathrm{~m}^{-2}$ ) & $18.1(876)$ \\
\hline \multicolumn{2}{|l|}{ Diabetes (self-reported) } \\
\hline Yes & $21.5(1074)$ \\
\hline No & $78.5(3367)$ \\
\hline \multicolumn{2}{|l|}{ Cognitive status } \\
\hline Intact & $83.4(3413)$ \\
\hline Mild $\mathrm{Cl}$ & $9.0(499)$ \\
\hline Moderate/severe $\mathrm{Cl}$ & $4.3(293)$ \\
\hline
\end{tabular}

Abbreviations: $\mathrm{Cl}$, cognitive impairment; HDB, Housing Development Board. aWeighted column \%, adjusted for oversampling and nonresponse using sample survey weights bercentages for following variables may not add up to $100 \%$ due to missing values: education $(n=11)$, body mass category $(n=164)$ and cognitive status $(n=236)$

cVocational/Institute of Technical Education/junior college/polytechnic/university and above.

${ }^{\mathrm{d} B u n g a l o w / t e r r a c e / s e m i d e t a c h / s h o p h o u s e / o t h e r . ~}$ men and women, DBP was significantly lower among women. Around half $(53.3 \%)$ of the elderly people had stage 1 or 2 hypertension as per the JNC-7 BP classification; the proportion increased with age and was higher among men (Table 2).

\section{Prevalence of hypertension and of awareness, treatment and control of hypertension}

Nearly three-fourths $(73.9 \%)$ of community-dwelling elderly Singaporeans had hypertension. Among them, nearly one-third were unaware that they had hypertension $(30.8 \%), 32.0 \%$ were untreated and three-fourths $(75.9 \%)$ had suboptimal BP control. Among those aware, only $1.9 \%$ were untreated. However, nearly two-thirds $(64.5 \%)$ of the treated hypertensives had suboptimal BP control (Figure 1).

The prevalence of hypertension varied across subgroups, rising above $80 \%$ among those aged $\geqslant 75$ years, Malays, those with low social participation, those with moderate/high risk body mass, those cognitively impaired and diabetic subjects. At the same time, some elderly subjects, such as those with secondary or higher education and those residing in condominiums, had a comparatively lower prevalence of hypertension. The prevalence of unaware and untreated hypertensives also varied, with the lowest prevalence among elderly people with diabetes (only 12.9\% were unaware and only $13.9 \%$ were untreated) and highest among those underweight (44.0\% were unaware and $48.4 \%$ were untreated). The highest prevalence of suboptimal BP control was observed among Malays $(87.8 \%$ of all Malay hypertensives and $80.0 \%$ of treated Malay hypertensives). The lowest prevalence of suboptimal BP control, for all hypertensives, was in subjects residing in condominiums $(68.2 \%)$, and for treated hypertensives, it was in underweight subjects (49.1\%; Table 3 ).

\section{Correlates of hypertension and of awareness, treatment and control} of hypertension

Although the odds of hypertension were significantly higher among men, those aged $\geqslant 65$ years, those with moderate/high risk body mass, those with moderate/severe cognitive impairment and those with diabetes, the odds were significantly lower among Indians, those residing in condominiums, those having greater social participation and those underweight. Elderly hypertensives aged $\geqslant 65$ years, those residing in larger public housing units or condominiums, those with high-risk body mass and those with diabetes were less likely to be unaware or untreated. However, men, Malays and those underweight were more likely to be unaware or untreated. Men and Malays also had higher odds of suboptimal BP control. In addition, higher odds were observed among those aged $\geqslant 65$ years, those with moderate/high risk body mass and those with diabetes. Increasing educational status, however, was associated with a decrease in the odds of suboptimal BP control (Table 4).

\section{DISCUSSION}

This study, arguably the first to comprehensively document the prevalence and correlates of hypertension and of awareness, treatment and control of hypertension among elderly Singaporeans, observed a high prevalence of hypertension (73.9\%) and, more importantly, of suboptimal BP control among all hypertensives (75.9\%) and among treated hypertensives (64.5\%). Age, gender, ethnicity, education, housing type, body mass and diabetes were significant correlates of being unaware of or untreated for hypertension and of suboptimal BP control. Although the specific 'at-risk' subgroups varied by the outcome considered, men and Malays consistently had higher odds for all three unfavorable outcomes. 
Table 2 Mean SBP and DBP, and JNC-7 blood pressure class, overall and by age and gender

\begin{tabular}{|c|c|c|c|c|c|c|}
\hline \multirow[b]{2}{*}{ Variables } & \multicolumn{2}{|c|}{$\begin{array}{c}\text { Blood pressure } \\
(m m \mathrm{Hg}), \text { Mean } \pm \text { s.d. }\end{array}$} & \multicolumn{4}{|c|}{ JNC-7 blood pressure class ${ }^{\mathrm{a}}$ Weighted row $\%^{\mathrm{b}}$ (n) } \\
\hline & $S B P$ & $D B P$ & $\begin{array}{c}\text { Normal } \\
S B P<120 \text { and } \\
D B P<80\end{array}$ & $\begin{array}{c}\text { Pre-HTN } \\
\text { SBP 120-139 or } \\
\text { DBP 80-89 }\end{array}$ & $\begin{array}{l}\text { Stage } 1 \text { HTN } \\
\text { SBP 140-159 or } \\
\text { DBP 90-99 }\end{array}$ & $\begin{array}{l}\text { Stage } 2 H T N \\
S B P \geqslant 160 \text { or } \\
D B P \geqslant 100\end{array}$ \\
\hline All $(N=4441)$ & $143.2 \pm 22.3$ & $77.7 \pm 11.4$ & $12.3(484)$ & $34.4(1448)$ & $32.7(1440)$ & $20.6(1069)$ \\
\hline $60-64(N=897)$ & $139.1 \pm 26.8$ & $79.2 \pm 14.0$ & $15.8(135)$ & $38.0(334)$ & $32.2(287)$ & $13.9(141)$ \\
\hline $65-74(N=1758)$ & $144.0 \pm 23.1$ & $78.2 \pm 11.5$ & $11.2(189)$ & $33.9(581)$ & $33.0(570)$ & $21.9(418)$ \\
\hline$\geqslant 75(N=1786)$ & $147.5 \pm 17.9$ & $74.7 \pm 9.3$ & $9.4(160)$ & $30.4(533)$ & $32.8(583)$ & $27.5(510)$ \\
\hline \multicolumn{7}{|l|}{ Gender $^{\mathrm{d}}$} \\
\hline Male $(N=2027)$ & $143.8 \pm 21.2$ & $78.6 \pm 11.2$ & $9.2(177)$ & $35.2(681)$ & $36.5(713)$ & $19.2(456)$ \\
\hline
\end{tabular}

Abbreviations: DBP, diastolic blood pressure; HTN, Hypertension; JNC-7, Joint National Committee on Prevention, Detection, Evaluation and Treatment of High Blood Pressure; SBP, systolic blood pressure.

assigned to higher category if falling into two categories.

bAdjusted for oversampling and nonresponse using sample survey weights.

CMean SBP and DBP (ANOVA), and proportion in JNC-7 BP class $\left(\chi^{2}\right.$ test) are significantly different $(P<0.05)$ across age categories.

dMean DBP (unpaired $t$-test), and proportion in JNC-7 BP class $\left(\chi^{2}\right.$ test) are significantly different $(P<0.05)$ across gender.

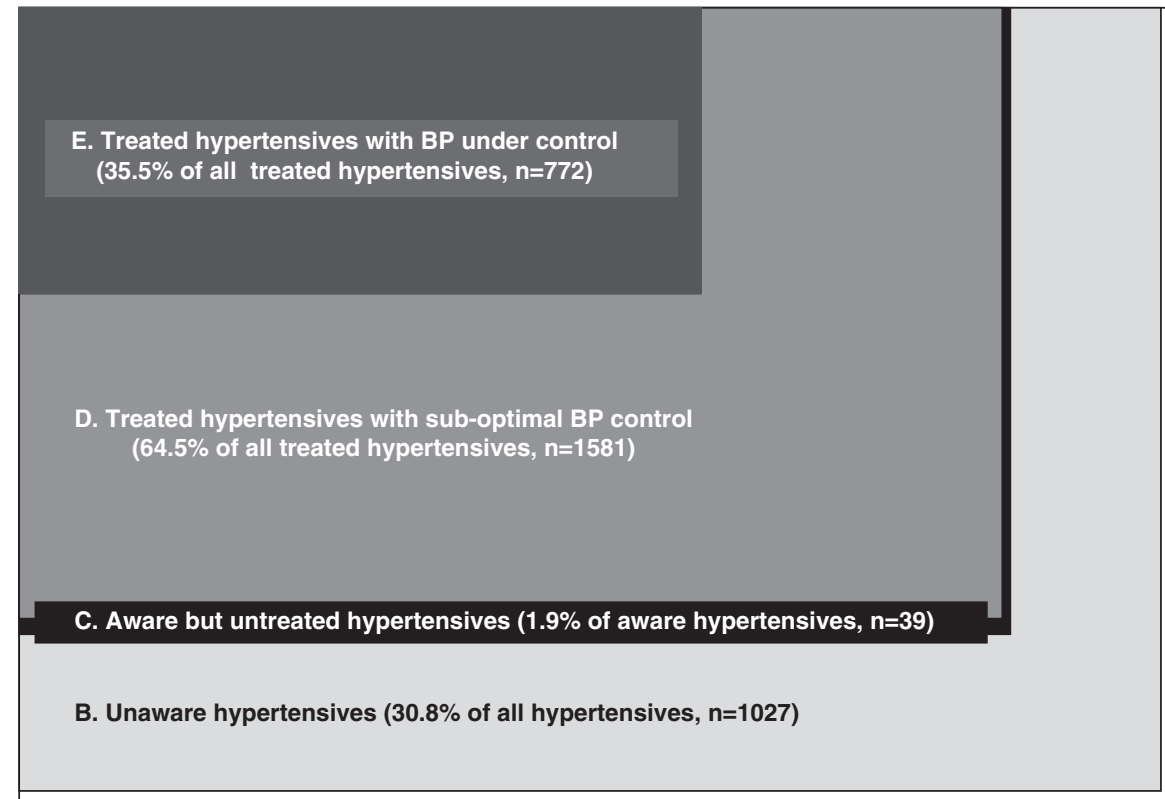

A. No Hypertension $(\mathbf{2 6 . 1} \%$ of all elderly Singaporeans, $n=1022)$

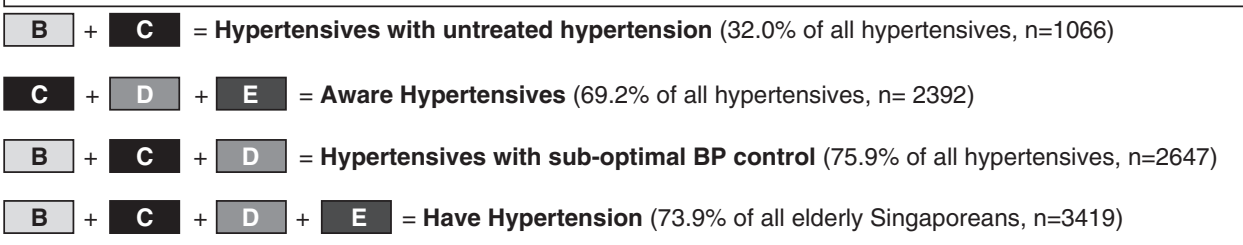

Figure 1 Hypertension and its awareness, treatment and control among elderly Singaporeans.

The various prevalences, given in Figure 1, do not entirely conform to the classic 'rule of halves,' which states that 'only half of hypertensives are detected (aware), half of which are treated, of which only half achieve adequate BP control. ${ }^{36,37}$ Nonconformity to the classic rule has been reported for most industrialized countries. ${ }^{36}$
The prevalence of hypertension and its awareness, treatment and control in studies conducted exclusively among the elderly and using our criteria for defining hypertension is given in Table 5. ${ }^{14,15,17,19-27}$ Although most of these studies reported a lower prevalence of hypertension ${ }^{17,20,22-25,27}$ than what we observed (73.9\%), some 
Table 3 Weighted prevalence of hypertension, unaware hypertensives, untreated hypertensives, hypertensives with BP not under control, and treated hypertensives with BP not under control by socio-demographic and health variables

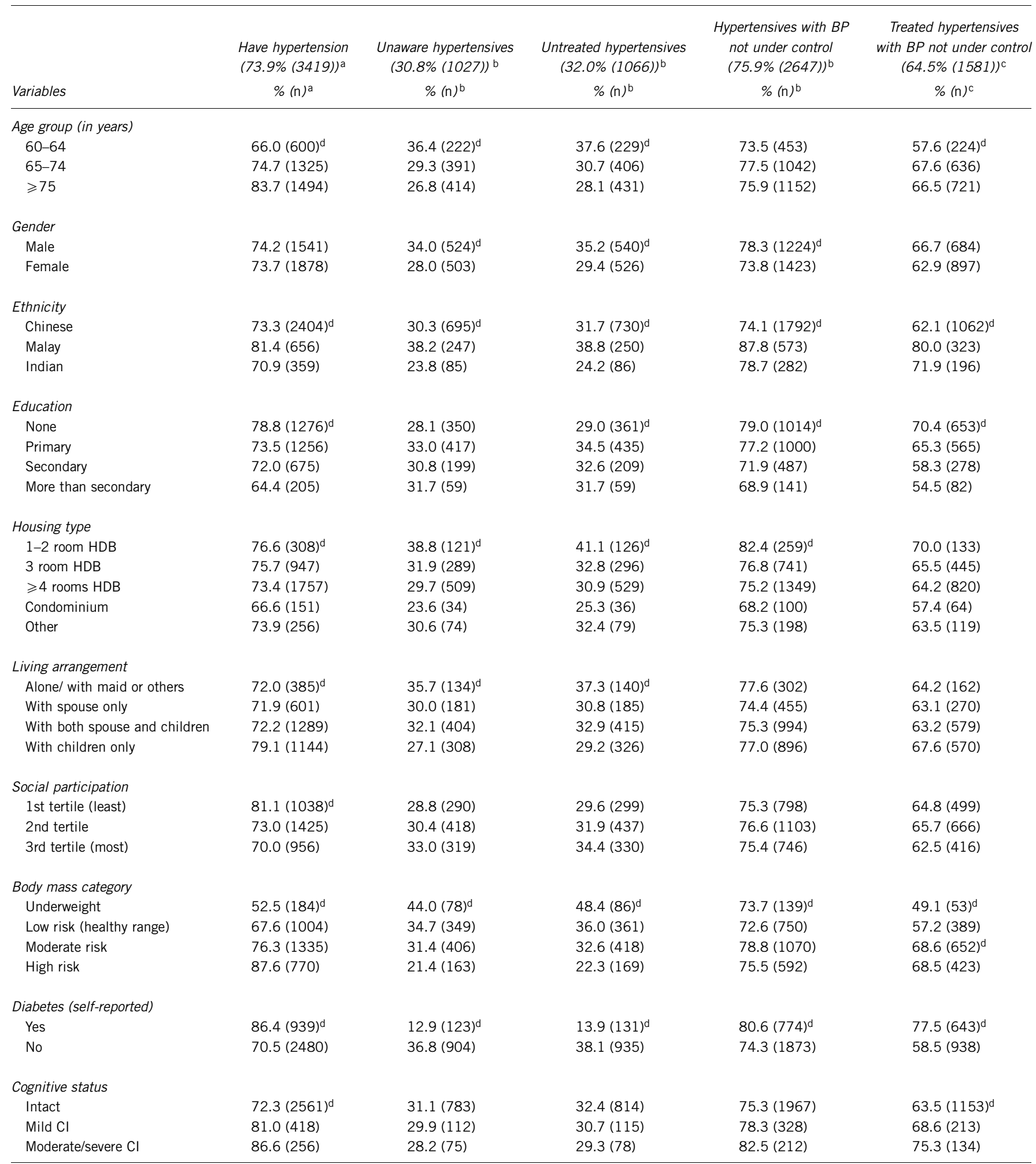

Abbreviations: BP, blood pressure; $\mathrm{Cl}$, cognitive impairment; $\mathrm{HDB}$, Housing Development Board.

aWeighted row \% (adjusted for oversampling and nonresponse using sample survey weights) and $n$ indicate weighted proportion and number who 'have hypertension' among all elderly in the corresponding row.

${ }^{b}$ Weighted row \% (adjusted for oversampling and nonresponse using sample survey weights) and $n$ indicate weighted proportion and number who have the outcome among those who are in the corresponding row in the 'Have hypertension' column.

'Weighted row \% (adjusted for oversampling and nonresponse using sample survey weights) and $n$ indicate weighted proportion and number who have suboptimal BP control among treated hypertensives (that is, among those who have hypertension and are on antihypertension medication).

dPercentages in different categories of the variable are significantly different ( $\chi^{2}$ test). 
Table 4 Adjusted odds ratios and $95 \%$ confidence intervals for association of socio-demographic and health variables among elderly Singaporeans with hypertension; hypertension unawareness, untreated hypertension and lack of BP control among hypertensives; and lack of BP control among treated hypertensives

\begin{tabular}{|c|c|c|c|c|c|}
\hline Variables & $\begin{array}{c}\text { Hypertension } \\
\mathrm{N}=4082^{\mathrm{a}}\end{array}$ & $\begin{array}{l}\text { Unaware of hypertension } \\
\text { (among hypertensives) } \\
\qquad \mathrm{N}=3137^{\mathrm{a}}\end{array}$ & $\begin{array}{l}\text { Untreated hypertension } \\
\text { (among hypertensives) } \\
\qquad \mathrm{N}=3137^{\mathrm{a}}\end{array}$ & $\begin{array}{l}\text { Lack of BP control } \\
\text { (among hypertensives) } \\
\quad \mathrm{N}=3137^{\mathrm{a}}\end{array}$ & $\begin{array}{l}\text { Lack of BP control } \\
\text { (among treated hypertensives) } \\
\qquad \mathrm{N}=2153^{\mathrm{a}}\end{array}$ \\
\hline $60-64$ & 1.0 & 1.0 & 1.0 & 1.0 & 1.0 \\
\hline $65-74$ & $1.48(1.25-1.74)$ & $0.75(0.62-0.91)$ & $0.76(0.63-0.92)$ & $1.16(0.95-1.42)$ & $1.37(1.09-1.73)$ \\
\hline$\geqslant 75$ & $2.60(2.04-3.31)$ & $0.60(0.47-0.77)$ & $0.60(0.47-0.76)$ & $1.00(0.77-1.29)$ & $1.33(1.01-1.77)$ \\
\hline \multicolumn{6}{|l|}{ Gender } \\
\hline Female & 1.0 & 1.0 & 1.0 & 1.0 & 1.0 \\
\hline Male & $1.31(1.11-1.54)$ & $1.29(1.07-1.56)$ & $1.29(1.07-1.56)$ & $1.67(1.37-2.04)$ & $1.65(1.32-2.06)$ \\
\hline \multicolumn{6}{|l|}{ Ethnicity } \\
\hline Chinese & 1.0 & 1.0 & 1.0 & 1.0 & 1.0 \\
\hline None & 1.0 & 1.0 & 1.0 & 1.0 & 1.0 \\
\hline Primary & $1.00(0.82-1.23)$ & $1.00(0.81-1.25)$ & $1.06(0.85-1.31)$ & $0.77(0.61-0.98)$ & $0.71(0.55-0.92)$ \\
\hline Secondary & $1.07(0.85-1.34)$ & $0.89(0.69-1.16)$ & $0.95(0.74-1.23)$ & $0.57(0.44-0.75)$ & $0.53(0.39-0.71)$ \\
\hline > Secondary & $0.85(0.62-1.15)$ & $0.93(0.65-1.35)$ & $0.90(0.62-1.30)$ & $0.49(0.34-0.72)$ & $0.44(0.29-0.68)$ \\
\hline \multicolumn{6}{|l|}{ Housing type } \\
\hline 1-2 room HDB & 1.0 & 1.0 & 1.0 & 1.0 & 1.0 \\
\hline 3 room HDB & $0.96(0.69-1.32)$ & $0.70(0.51-0.97)$ & $0.65(0.47-0.90)$ & $0.85(0.58-1.25)$ & $1.08(0.70-1.67)$ \\
\hline$\geqslant 4$ rooms $\mathrm{HDB}$ & $0.83(0.61-1.15)$ & $0.65(0.47-0.90)$ & $0.61(0.45-0.84)$ & $0.86(0.59-1.25)$ & $1.13(0.74-1.74)$ \\
\hline Condominium & $0.59(0.38-0.91)$ & $0.50(0.30-0.84)$ & $0.51(0.31-0.84)$ & $0.66(0.39-1.11)$ & $0.96(0.53-1.72)$ \\
\hline Other & $0.93(0.62-1.41)$ & $0.76(0.49-1.17)$ & $0.74(0.48-1.14)$ & $1.00(0.62-1.62)$ & $1.26(0.73-2.18)$ \\
\hline 2nd tertile & $0.72(0.58-0.88)$ & $1.00(0.81-1.23)$ & $1.04(0.84-1.28)$ & $1.23(0.99-1.52)$ & $1.25(0.98-1.58)$ \\
\hline 3rd tertile (most) & $0.61(0.49-0.77)$ & $1.17(0.93-1.46)$ & $1.20(0.96-1.51)$ & $1.19(0.94-1.51)$ & $1.13(0.87-1.47)$ \\
\hline \multicolumn{6}{|l|}{ Body mass category } \\
\hline Underweight & $0.46(0.35-0.61)$ & $1.38(0.96-1.99)$ & $1.55(1.08-2.23)$ & $0.97(0.65-1.45)$ & $0.65(0.40-1.06)$ \\
\hline Low risk (healthy range) & 1.0 & 1.0 & 1.0 & 1.0 & 1.0 \\
\hline Moderate risk & $1.61(1.37-1.90)$ & $0.87(0.72-1.05)$ & $0.87(0.73-1.05)$ & $1.40(1.15-1.71)$ & $1.56(1.25-1.96)$ \\
\hline High risk & $3.57(2.77-4.60)$ & $0.49(0.38-0.62)$ & $0.49(0.39-0.63)$ & $1.02(0.80-1.29)$ & $1.39(1.07-1.81)$ \\
\hline \multicolumn{6}{|l|}{ Diabetes (self-reported) } \\
\hline No & 1.0 & 1.0 & 1.0 & 1.0 & 1.0 \\
\hline Yes & $2.28(1.84-2.83)$ & $0.26(0.20-0.32)$ & $0.26(0.21-0.33)$ & $1.34(1.09-1.65)$ & $2.21(1.78-2.75)$ \\
\hline \multicolumn{6}{|l|}{ Cognitive status } \\
\hline Intact & 1.0 & 1.0 & 1.0 & 1.0 & 1.0 \\
\hline Mild Cl & $1.26(0.94-1.68)$ & $1.08(0.81-1.44)$ & $1.05(0.79-1.39)$ & $1.03(0.76-1.41)$ & $0.96(0.68-1.35)$ \\
\hline Moderate/severe $\mathrm{Cl}$ & $1.87(1.12-3.12)$ & $1.05(0.69-1.59)$ & $1.03(0.68-1.55)$ & $1.45(0.91-2.32)$ & $1.58(0.95-2.63)$ \\
\hline
\end{tabular}


Table 5 Prevalence of HTN, unaware hypertensives, untreated hypertensives and suboptimal BP control in studies focusing exclusively on the elderly and defining hypertension as 'SBP $\geqslant 140$ or DBP $\geqslant 90$ or current use of anti-hypertension medication'

\begin{tabular}{|c|c|c|c|c|c|c|c|c|c|}
\hline \multirow[b]{2}{*}{ First author, year } & \multirow[b]{2}{*}{ Country } & \multirow[b]{2}{*}{$\mathrm{N}$} & \multirow[b]{2}{*}{ Age } & \multirow[b]{2}{*}{$H T N^{a}$} & \multicolumn{3}{|c|}{ Among hypertensives } & \multirow[b]{2}{*}{$\begin{array}{c}\text { Suboptimal BP control among } \\
\text { treated hypertensives }{ }^{c}\end{array}$} & \multirow[b]{2}{*}{$\begin{array}{c}\text { Untreated among } \\
\text { aware }^{\mathrm{b}}\end{array}$} \\
\hline & & & & & Unaware & Untreated $^{\mathrm{b}}$ & $\begin{array}{l}\text { Suboptimal } \\
\text { BP controlc }\end{array}$ & & \\
\hline Present study & Singapore & 4441 & $\geqslant 60$ & $73.90 \%$ & $30.30 \%$ & $32.00 \%$ & $75.9 \%{ }^{d}$ & $64.5 \%{ }^{d}$ & $1.90 \%$ \\
\hline Zhang et al. ${ }^{27}$ & China & 4141 & $\geqslant 60$ & $48.50 \%$ & $24.70 \%$ & $33.3 \%{ }^{\mathrm{e}}$ & $67.90 \%$ & $51.80 \%$ & $11.4 \%^{f}$ \\
\hline Porapakkham et al. ${ }^{24}$ & Thailand & 19374 & $\geqslant 60$ & $51.10 \%$ & $56.10 \%$ & $84.2 \%^{f}$ & $98.3 \%^{f}$ & $89.40 \%$ & $63.90 \%$ \\
\hline Hypertension study group, ${ }^{17}$ & $\begin{array}{l}\text { India and } \\
\text { Bangladesh }\end{array}$ & 1203 & $\geqslant 60$ & $65.00 \%$ & $55.30 \%$ & $60.40 \%$ & $89.80 \%$ & $74.40 \%$ & $11.4 \%{ }^{f}$ \\
\hline Kim et al. ${ }^{19}$ & Korea & 995 & $\geqslant 65$ & $68.70 \%$ & - & $33.90 \%$ & $83.6 \%$ d & $75.2 \%{ }^{d}$ & - \\
\hline Lu et al. ${ }^{20}$ & Taiwan & 1435 & $\geqslant 65$ & $60.40 \%$ & $48.50 \%$ & - & - & - & - \\
\hline Méndez-Chacón et al. ${ }^{22}$ & Costa Rica & 2800 & $\geqslant 60$ & $64.50 \%$ & $25.10 \%$ & - & $\sim 50 \%$ & - & $18.90 \%$ \\
\hline Brindel et al. ${ }^{15}$ & France & 9090 & $\geqslant 65$ & $78.20 \%$ & - & - & - & $31.00 \%$ & - \\
\hline Skliros et al. ${ }^{26}$ & Greece & 615 & $\geqslant 65$ & $69.10 \%$ & $11.00 \%$ & $19.1 \%^{\dagger}$ & $60.2 \%^{f}$ & $50.90 \%$ & $9.00 \%$ \\
\hline Prencipe et al. ${ }^{25}$ & Italy & 1032 & $\geqslant 65$ & $64.80 \%$ & $34.40 \%$ & $40.50 \%$ & $89.50 \%$ & $82.40 \%$ & - \\
\hline Banegas et al. ${ }^{14}$ & Spain & 4009 & $\geqslant 60$ & $68.30 \%$ & $35.00 \%$ & $44.70 \%$ & $83.60 \%$ & $70.50 \%$ & $14.90 \%$ \\
\hline McDonald et al. ${ }^{21}$ & USA & 3810 & $\geqslant 65$ & $70.80 \%$ & $24.10 \%$ & $30.70 \%$ & $66.2 \%^{f}$ & $51.20 \%$ & $8.7 \%{ }^{f}$ \\
\hline Ostchega et al. ${ }^{23}$ & USA & 5093 & $\geqslant 60$ & $58.00 \%$ & $30.00 \%$ & $42.00 \%$ & $79.1 \% \mathrm{~d}, \mathrm{f}$ & $64.0 \%{ }^{d}$ & $17.1 \% \mathrm{e}$ \\
\hline Ostchega et al. ${ }^{23}$ & USA & 4710 & $\geqslant 60$ & $67.00 \%$ & $26.00 \%$ & $33.00 \%$ & $71.2 \% \mathrm{~d}, \mathrm{f}$ & $57.0 \%{ }^{d}$ & $9.5 \%^{f}$ \\
\hline \multicolumn{10}{|c|}{ Studies from Singapore (Note: definition of hypertension is different-see footnotes $g$ and $h$ ) } \\
\hline Ho et al. ${ }^{16}$ & Singapore & 265 & $\geqslant 65$ & $55.5 \% \mathrm{~g}$ & $28.00 \%$ & - & $73.40 \%$ & - & - \\
\hline Joshi et al. ${ }^{18}$ & Singapore & 19848 & $\geqslant 65$ & $55.5 \%{ }^{\mathrm{h}}$ & - & - & - & - & - \\
\hline
\end{tabular}

Abbreviations: BP, blood pressure; DBP, diastolic blood pressure; HTN, hypertension; SBP, systolic blood pressure.

${ }^{a} \mathrm{SBP} \geqslant 140$ or $\mathrm{DBP} \geqslant 90$ or current use of anti-hypertension medication,' unless otherwise indicated.

${ }^{b}$ 'Currently not on antihypertension medication,' unless otherwise indicated.

b'Currently not on antihypertension medication,' unless otherwise indicatec
c'SBP $\geqslant 140 \mathrm{~mm} \mathrm{Hg}$ or DBP $\geqslant 90 \mathrm{~mm} \mathrm{Hg}$,' unless otherwise indicated.

'SBP $\geqslant 140 \mathrm{~mm} \mathrm{Hg}$ or DBP $\geqslant 90 \mathrm{~mm} \mathrm{Hg}$,' unless otherwise indicated.
d'SBP $\geqslant 140 \mathrm{~mm} \mathrm{Hg}$ or DBP $\geqslant 90 \mathrm{~mm} \mathrm{Hg}$ ' for non-diabetics, and 'SBP $\geqslant 130 \mathrm{~mm} \mathrm{Hg}$ or DBP $\geqslant 80 \mathrm{~mm} \mathrm{Hg}$ ' for diabetics.

e'Currently not a user of anti-hypertension medication and/or lifestyle change.'

'Derived \% (not given in the actual paper), calculated based on available numbers and percentages, may be inaccurate as it does not take sampling weight into account.

gNo definition given.

h'SBP $\geqslant 140$ or DBP $\geqslant 90$.'

reported a similar prevalence ${ }^{14,19,21,23,26}$ or, in one study, ${ }^{15}$ an even higher prevalence. Other than differences in the BP measurement instrument (manual or electronic) and number of readings (two or three) used for defining SBP and DBP, the variation could also reflect differences in demographic (for example, age, gender, ethnicity) and lifestyle (for example, diet, physical activity) profiles and in economic development across countries (prevalence is usually higher in more developed economies ${ }^{38}$ ). Although previous studies of the elderly in Singapore have reported a lower prevalence, ${ }^{16,18}$ one of these studies ${ }^{16}$ was limited to a single township and the other ${ }^{18}$ did not consider use of antihypertension medication in the definition. Another Singaporean study using the same definition of hypertension as we did, although not limited to the elderly, did report a prevalence of hypertension among those aged $\geqslant 65$ years that was comparable with our findings. ${ }^{6}$

Similar to previous studies, ${ }^{14,16-18,20,22,23,25,26}$ we observed hypertension to be associated with age, higher BMI and diabetes. We also observed elderly men to be at a higher risk of hypertension, whereas previous studies have reported either no association with gender, ${ }^{17,20}$ or a higher risk for women. ${ }^{14,18}$ Furthermore, although elderly Malays had a higher prevalence of hypertension than elderly Chinese, the relationship disappeared in the adjusted analysis, possibly due to the greater prevalence of diabetes and higher BMI categories among Malays. Previous reports suggest an inverse association between hypertension and socioeconomic status, represented by education and/or income. ${ }^{14,17,39}$ We observed the same, with a lower prevalence among those with higher education or more spacious housing. However, in the adjusted analysis, only housing remained significant. Interestingly, elderly people with greater social participation had a lower prevalence of hypertension. Previous studies have also reported social participation to be beneficial for various health outcomes, including coronary diseases. ${ }^{40,41}$ Those with moderate/severe cognitive impairment were more likely to be hypertensive, possibly reflecting the fact that hypertension is a risk factor for cognitive impairment and dementia, especially of vascular etiology. ${ }^{1,42,43}$

The proportions of unaware $(30.3 \%)$ or untreated $(32.0 \%)$ hypertensives in this study were lower than most studies from other countries, ${ }^{14,17,20,24,25}$ although a few studies ${ }^{21,23,26,27}$ reported similar or even lower figures. Furthermore, only $1.9 \%$ of those aware (that is, diagnosed) were untreated, which is much lower than figures reported from other countries. ${ }^{14,17,21-24,27}$ Previous studies from Singapore reported comparable figures. ${ }^{6,16}$

The levels of awareness of hypertension and its treatment are contingent on efforts aimed at raising awareness about hypertension (or chronic diseases in general) as well as the efficiency of health-care services in detecting hypertension and initiating treatment. The comparatively lower proportion of unaware or untreated hypertensives in Singapore may be due in part to good awareness and screening programs and to the health-care services in the country. The NHLP (National Healthy Lifestyles Program) has been ongoing in Singapore since 1992.44,45 Although hypertension is not its key focus, the program's focus on a healthy lifestyle might have had an indirect 
benefit in raising awareness about hypertension. The nationwide awareness and screening program for renal disease risk factors, including hypertension, by the National Kidney Foundation Singapore, ${ }^{18,46,47}$ the Integrated Screening Program ${ }^{48,49}$ and a comprehensive chronic disease management approach at the primary health-care level ${ }^{50}$ are also likely contributors. Even so, there is clearly room for improvement, with 30.3 and $32.0 \%$ hypertensives still being unaware of and untreated for the disease, respectively.

Furthermore, the groups of elderly hypertensives who are more likely to be unaware and/or untreated need greater attention. For some such groups, including those $<65$ years old, those underweight and those without diabetes, the increased risk could reflect complacency on their and/or their health-care providers' part, as these groups may not be traditionally considered to be at risk of hypertension. A related reason could be their lower frequency of contact with the health-care system, allowing less opportunity for diagnosis and treatment. The lower risk among those with higher BMI supports these conjectures. Of even greater concern is the increased risk of being unaware and untreated among men and Malays, who have a high prevalence of hypertension. The greater risk among those of lower socioeconomic status (residing in 1 to 2 rooms public housing) could be due to less access to or use of health-care services; this, however, was not ascertained in this study.

An even greater effort is required to lower BP to defined control levels. Around three-fourths of all hypertensives and $64.5 \%$ of treated hypertensives had suboptimal BP control in this study. Furthermore, more than one-third $(35.1 \%)$ of the latter had stage 2 hypertension, as defined by JNC-7. Even using a cutoff of $<140 / 90 \mathrm{~mm} \mathrm{Hg}$ for all subjects, the prevalence of suboptimal control remained high $(72.0 \%$ among all hypertensives and $58.8 \%$ among treated hypertensives). A comparison with other studies (Table 5) reveals that suboptimal BP control is not limited to Singapore; most studies report comparable or even higher figures.

Although suboptimal BP control among all hypertensives can be attributed in part to being unaware or untreated, suboptimal BP control among treated hypertensives cannot, and a variety of reasons have been suggested for this fact. These include health system factors such as access and cost, physician factors such as prescription of inadequate medication, doctor-patient communication quality and inadequate awareness of or compliance with guidelines, and patient nonadherence to medication due to reasons such as low (health) literacy, cost, side effects, forgetfulness and lack of knowledge of the disease. ${ }^{1,19,27,51-53}$ These factors, not assessed in this survey, should be explored in future quantitative and qualitative studies.

The use of the average of three BP measures assessed at a single visit (due to time and financial constraints) to define SBP and DBP values might have overestimated the prevalence of hypertension and underestimated the prevalence of awareness and BP control. Many previous population-based surveys also report findings based on BP values measured during a single visit., ${ }^{6,15-17,19-22,24,27}$ Given the survey's cross-sectional design, the identified correlates of hypertension are not necessarily causal risk factors. However, most of the sociodemographic variables we consider must have preceded the development of hypertension. Although our findings can be generalized to community-dwelling elderly Singaporeans, the situation is likely to be different among younger Singaporeans, which can be gauged from other studies and surveys. ${ }^{6,30}$ Classification of individuals as treated or untreated was based on self-reported use of antihypertension medication. Furthermore, information on the number, type and dose of prescribed drugs and on health-care utilization was not collected in the survey, limiting our understanding of reasons for the high prevalence of suboptimal BP control.
This study has several strengths. It is based on a large and representative sample. The response rate of $69.4 \%$ was higher than the typical response rate for surveys conducted in this population and age group. The definitions used for hypertension and for awareness, treatment and control of hypertension are based on standard guidelines and have been used extensively in previous studies, $1,14,15,17,19-27$ allowing the comparisons in the discussion above. The BP measures were obtained using electronic BP monitors, possibly reducing interobserver variability, and in accordance with given instructions for nearly all participants.

The study findings suggest that there is a definite need for improving awareness, treatment and, especially, control of hypertension among elderly Singaporeans. To improve awareness, a specific focus on hypertension, highlighting its high prevalence, easy detection through noninvasive BP measurement and amenability to control, should be considered for the annual campaigns undertaken as part of the NHLP. The availability of the subsidized Integrated Screening Program $^{48,49}$ should also be promoted. A simultaneous focus on primary prevention through lifestyle modification should be maintained. Health-care providers should be asked to take BP measurements for all elderly patients at all possible encounters. As nearly all hypertensives who were aware of their condition were also under treatment, these measures are also likely to reduce the prevalence of untreated hypertensives.

Health-care providers should strive to attain BP control among all elderly hypertensives under their treatment. Those aged $\geqslant 65$ years, men, Malays, the uneducated, those with higher BMI and those with diabetes mandate greater attention. The reasons for poor control in these subgroups needs to be ascertained in future studies to help providers improve BP control among their at-risk elderly patients. Considering long-term medication cost to be a key impediment to medication compliance and thereby BP control, the Singapore government launched the CDMP (Chronic Disease Management Program) in October $2006 .{ }^{54}$ Under the CDMP, an individual can use his/her compulsory individual medical savings (Medisave) account to pay for consultation and drugs for six diseases, including hypertension. This could possibly enhance detection and control of hypertension among the elderly. Assessment of the impact of such programs or initiatives at the population level requires regular data collection efforts based on representative samples. One possibility is to expand the age base of future National Health Surveys in Singapore, conducted every 6 years, to include all the elderly.

\section{Conclusion}

We observed a high prevalence of hypertension among elderly Singaporeans (73.9\%) and more importantly, suboptimal BP control among all hypertensives (75.9\%) and treated hypertensives (64.5\%). Age, gender, ethnicity, education, housing, body mass and diabetes were significant correlates of being unaware of and untreated for hypertension and of suboptimal BP control. Although the specific 'atrisk' subgroups varied by the outcome considered, men and Malays had higher odds for all three unfavorable outcomes. There is a definite need for improving awareness, treatment and, especially, control of hypertension among elderly Singaporeans. Primary and secondary prevention efforts targeting the elderly themselves and their primary health-care providers and regular data collection efforts based on representative samples are indicated.

\section{CONFLICT OF INTEREST}

The authors declare no conflict of interest. 


\section{ACKNOWLEDGEMENTS}

The data for this manuscript were collected through a project funded by the Ministry of Community Development, Youth and Sports, Singapore. The analyses were in part funded by a generous grant from the Tsao Foundation, Singapore, and an $A^{\star}$ STAR infrastructure grant to the Duke-NUS Program in Health Services and Systems Research.

1 Joint National Committee on Prevention Detection Evaluation and Treatment of High Blood Pressure. The Seventh Report of the Joint National Committee on Prevention, Detection, Evaluation, and Treatment of High Blood Pressure: Complete Report. The Program: Bethesda, MD 2004.

2 Rigaud AS, Forette B. Hypertension in older adults. J Gerontol A Biol Sci Med Sci 2001; 56: M217-M225.

3 Ezzati M, Lopez AD, Rodgers A, Vander Hoorn S, Murray CJ. Selected major risk factors and global and regional burden of disease. Lancet 2002; 360: 1347-1360.

4 Hajiar I, Kotchen TA. Trends in prevalence, awareness, treatment, and control of hypertension in the United States, 1988-2000. JAMA 2003; 290: 199-206.

5 Whelton PK, He J, Muntner P. Prevalence, awareness, treatment and control of hypertension in North America, North Africa and Asia. J Hum Hypertens 2004; 18 545-551.

6 Wu Y, Tai ES, Heng D, Tan CE, Low LP, Lee J. Risk factors associated with hypertension awareness, treatment, and control in a multi-ethnic Asian population. J Hypertens 2009; 27: 190-197.

7 Pedelty L, Gorelick PB. Management of hypertension and cerebrovascular disease in the elderly. Am J Med 2008; 121: S23-S31.

8 Vasan RS, Beiser A, Seshadri S, Larson MG, Kannel WB, D'Agostino RB, Levy D. Residual lifetime risk for developing hypertension in middle-aged women and men: the Framingham Heart Study. JAMA 2002; 287: 1003-1010.

9 Beckett NS, Peters R, Fletcher AE, Staessen JA, Liu L, Dumitrascu D, Stoyanovsky V, Antikainen RL, Nikitin Y, Anderson C, Belhani A, Forette F, Rajkumar C, Thijs L, Banya W, Bulpitt CJ. Treatment of hypertension in patients 80 years of age or older. N Eng/ Med 2008; 358: 1887-1898.

10 Rashidi A, Wright JT. Drug treatment of hypertension in older hypertensives. Clin Geriatr Med 2009; 25: 235-244.

11 Andrawes WF, Bussy C, Belmin J. Prevention of cardiovascular events in elderly people. Drugs Aging 2005; 22: 859-876.

12 Prisant LM, Moser M. Hypertension in the elderly: can we improve results of therapy? Arch Intern Med 2000; 160: 283-289.

13 Mulrow CD, Cornell JA, Herrera CR, Kadri A, Farnett L, Aguilar C. Hypertension in the elderly. Implications and generalizability of randomized trials. JAMA 1994; 272: 1932-1938.

14 Banegas JR, Rodriguez-Artalejo F, Ruilope LM, Graciani A, Luque M, de la Cruz-Troca JJ, Garcia-Robles R, Tamargo J, Rey-Calero J. Hypertension magnitude and management in the elderly population of Spain. J Hypertens 2002; 20: 2157-2164.

15 Brindel P, Hanon O, Dartigues JF, Ritchie K, Lacombe JM, Ducimetiere P, Alperovitch A, Tzourio C. Prevalence, awareness, treatment, and control of hypertension in the elderly: the Three City study. J Hypertens 2006; 24: 51-58.

16 Ho HK, Cheong SK, Siew CW, Tan BY, Lim FS, Emmanuel SC. Prevalence, awareness and control of hypertension in community-dwelling elderly in Singapore. Ann Acad Med Singapore 2003; 32: S58-S59.

17 Hypertension Study Group. Prevalence, awareness, treatment and control of hypertension among the elderly in Bangladesh and India: a multicentre study. Bull World Health Organ 2001; 79: 490-500.

18 Joshi V, Lim J, Nandkumar M. Prevalence and risk factors of undetected elevated blood pressure in an elderly Southeast Asian population. Asia Pac J Public Health 2007; 19: 3-9.

19 Kim KI, Chang HJ, Cho YS, Youn TJ, Chung WY, Chae IH, Choi DJ, Kim CH. Current status and characteristics of hypertension control in community resident elderly Korean people: data from a Korean longitudinal study on health and aging (KLoSHa study). Hypertens Res 2008; 31: 97-105.

20 Lu FH, Tang SJ, Wu JS, Yang YC, Chang CJ. Hypertension in elderly persons: its prevalence and associated cardiovascular risk factors in Tainan City, southern Taiwan. J Gerontol A Biol Sci Med Sci 2000; 55: M463-M468.

21 McDonald M, Hertz RP, Unger AN, Lustik MB. Prevalence, awareness, and management of hypertension, dyslipidemia, and diabetes among United States adults aged 65 and older. J Gerontol A Biol Sci Med Sci 2009; 64: 256-263.

22 Mendez-Chacon E, Santamaria-Ulloa C, Rosero-Bixby L. Factors associated with hypertension prevalence, unawareness and treatment among Costa Rican elderly. BMC Public Health 2008; 8: 275 .

23 Ostchega Y, Dillon CF, Hughes JP, Carroll M, Yoon S. Trends in hypertension prevalence, awareness, treatment, and control in older U.S. adults: data from the National Health and Nutrition Examination Survey 1988 to 2004. J Am Geriatr Soc 2007; 55: 1056-1065.

24 Porapakkham Y, Pattaraarchachai J, Aekplakorn W. Prevalence, awareness, treatment and control of hypertension and diabetes mellitus among the elderly: the 2004
National Health Examination Survey III, Thailand. Singapore Med J 2008; 49: 868-873.

25 Prencipe M, Casini AR, Santini M, Ferretti C, Scaldaferri N, Culasso F. Prevalence, awareness, treatment and control of hypertension in the elderly: results from a population survey. J Hum Hypertens 2000; 14: 825-830.

26 Skliros EA, Papaioannou I, Sotiropoulos A, Giannakaki G, Milingou M, Lionis C. A high level of awareness but a poor control of hypertension among elderly Greeks. The Nemea primary care study. J Hum Hypertens 2002; 16: 285-287.

27 Zhang X, Zhu M, Dib HH, Hu J, Tang S, Zhong T, Ming X. Knowledge, awareness, behavior (KAB) and control of hypertension among urban elderly in Western China. Int J Cardiol 2009; 137: 9-15.

28 Committee on Ageing Issues. Report on the Ageing Population. Ministry of Community Development, Youth and Sports: Singapore, 2006.

29 Singapore Department of Statistics. Population Trends 2009. Ministry of Trade \& Industry, Republic of Singapore: Singapore, 2009.

30 Singapore Ministry of Health. Epidemiology and Disease Control Division. National Health Survey 2004: Singapore. Ministry of Health: Singapore, 2005.

31 Singapore Ministry of Health., Singapore Heart Foundation., College of Family Physicians (Singapore), Singapore Medical Association (Singapore), Singapore Cardiac Society., Academy of Medicine Singapore., Singapore Hypertension Society., National Committee on Cardiac Care., Joint Cardiovascular Working Committee (Singapore). Hypertension. Ministry of Health: Singapore, 2005.

32 Ellaway A, Macintyre S. Is social participation associated with cardiovascular disease risk factors? Soc Sci Med 2007; 64: 1384-1391.

33 Health Promotion Board. Revision of Body Mass Index (BMI) Cut-Offs in Singapore 2005. http://www.hpb.gov.sg/hpb/default.asp?TEMPORARY_DOCUMENT=1769 \&TEMPORARY TEMPLATE $=2$. (accessed 15 October 2009).

34 WHO expert consultation. Appropriate body-mass index for Asian populations and its implications for policy and intervention strategies. Lancet 2004; 363: 157-163.

35 Pfeiffer E. A short portable mental status questionnaire for the assessment of organic brain deficit in elderly patients. J Am Geriatr Soc 1975; 23: 433-441.

36 Marques-Vidal P, Tuomilehto J. Hypertension awareness, treatment and control in the community: is the 'rule of halves' still valid? J Hum Hypertens 1997; 11: 213-220.

37 Wilber JA, Barrow JG. Hypertension—a community problem. Am J Med 1972; 52 : 653-663.

38 Pereira M, Lunet N, Azevedo A, Barros H. Differences in prevalence, awareness, treatment and control of hypertension between developing and developed countries. J Hypertens 2009; 27: 963-975.

39 Kaplan MS, Nunes A. The psychosocial determinants of hypertension. Nutr Metab Cardiovasc Dis 2003; 13: 52-59.

40 Bath PA, Deeg D. Social engagement and health outcomes among older people: introduction to a special section. Eur J Ageing 2005; 2: 24-30.

41 Sundquist K, Lindstrom M, Malmstrom M, Johansson SE, Sundquist J. Social participation and coronary heart disease: a follow-up study of 6900 women and men in Sweden. Soc Sci Med 2004; 58: 615-622.

42 Grossman H, Bergmann C, Parker S. Dementia: a brief review. Mt Sinai J Med 2006; 73: 985-992.

43 Qiu C, De Ronchi D, Fratiglioni L. The epidemiology of the dementias: an update. Curr Opin Psychiatry 2007; 20: 380-385.

44 Bhalla V, Fong CW, Chew SK, Satku K. Changes in the levels of major cardiovascular risk factors in the multi-ethnic population in Singapore after 12 years of a national non-communicable disease intervention programme. Singapore Med J 2006; 47: 841-850.

45 Cutter J, Tan BY, Chew SK. Levels of cardiovascular disease risk factors in Singapore following a national intervention programme. Bull World Health Organ 2001; 79: 908-915.

46 Ramirez SP. A comprehensive public health approach to address the burden of renal disease in Singapore. J Am Soc Nephrol 2003; 14: S122-S126.

47 Ramirez SP, McClellan W, Port FK, Hsu SI. Risk factors for proteinuria in a large, multiracial, southeast Asian population. J Am Soc Nephrol 2002; 13: 1907-1917.

48 Health Promotion Board. Health Programmes. Integrated Screening Programme 2007. http://www.hpb.gov.sg/hpb/default.asp?pg id=3497. (accessed 24 October 2009).

49 Khalik S. Singapore starts national screening programme for older people. Lancet 2001; 358: 736 .

50 Cheah J. Chronic disease management: a Singapore perspective. Br Med J 2001; 323 : 990-993.

51 Berlowitz DR, Ash AS, Hickey EC, Friedman RH, Glickman M, Kader B, Moskowitz MA. Inadequate management of blood pressure in a hypertensive population. $N$ Engl J Med 1998; 339: 1957-1963.

52 Oliveria SA, Lapuerta P, McCarthy BD, L'Italien GJ, Berlowitz DR, Asch SM. Physicianrelated barriers to the effective management of uncontrolled hypertension. Arch Intern Med 2002; 162: 413-420.

53 Redon J, Brunner HR, Ferri C, Hilgers KF, Kolloch R, van Montfrans G. Practical solutions to the challenges of uncontrolled hypertension: a white paper. $J$ Hypertens Supp/ 2008; 26: S1-14.

54 Health Promotion Board. A Way to Reduce Outpatient Cost for Chronic Disease 2009. http://www.hpb.gov.sg/chronicdiseases/article.aspx?id=3420. (accessed 24 October 2009). 